\title{
Observations on the connection of the 11-year Solar Cycle and the El Niño and La Niña phenomena and rainfall in the Amazon (1980-2030).
}

\author{
Newton Silva de Lima* ${ }^{*}$, Eriberto Façanha ${ }^{*}+$, Alan dos Santos Ferreira ${ }^{*}$, Liliam Greicy ${ }^{*}$. Aldemir \\ Malveira $^{\dagger+\dagger}$, José Cavalcante ${ }^{\dagger \dagger^{*}}$, Alfredo Tadeu Coimbra, Roseilson Souza do Vale ${ }^{\ddagger}$, Daniel Valentim \\ Mansur", Naiana Lopes \\ *Lutheran University Center of Manaus (Geosciences - Mathematics) / ${ }^{\dagger}$ Federal University of Amazonas (Mathematics)/ \\ ${ }^{\ddagger}$ Federal University of West of Pará (Geosciences), ${ }^{\dagger \dagger}$ (Secretary of Education and Quality of Teaching of the State of \\ Amazonas). ${ }^{\dagger \dagger^{*}}$ Federal Institute of Amazonas, Federal University of Juiz de Fora, Université de Genève - Faculté \\ SCIENCES \\ ††* ${ }^{*}$ Manaus/ ${ }^{\ddagger}$ Santarém (PA-Brazil)/\#Juiz de Fora (MG-Brazil), Genève \\ (newtonulbra@gmail.com, eribertofacanha@seduc.net, alans_ferreira@hotmail.com, amoliveira@gmail.com, \\ liliam_gso@yahoo.com.br, alfredocoimbra@seduc.net, psi.josecavalcante@gmail.com, roseilsondovale@gmail.com, \\ danielvmansur@gmail.com, naiana.lopes@etu.unige.ch)
}

\begin{abstract}
The stochastic bias was used to describe the correlation between the 11-year solar cycle compared to the El Niño Southern Oscillation (ENSO) time series and rainfall over the city of Manaus (Brazil), looking for a connection between these events. For this, the time series of Solar Spots and El Niño and La Niña events and rainfall over Manaus were studied by means of the time series tools for the investigated periods. This operational research work shows that from 1980 until the 2030 projection, there is a strong correlation of connection of these data to the observed phenomena.
\end{abstract}

Keywords - Connection, Solar Cycle 11 years, El Niño, La Niña, Amazon.

\section{INTRODUCTION}

Changes in atmospheric circulation in the tropical zone (Walker cell) induce change in rainfall patterns, devastating floods, and severe droughts that can drastically affect the lives of millions of people [1]. In the mosaic of landscapes that is tropical South America the tendencies for rainfall, in the Amazon in eastern Brazil, to the northwest of Peru are well-defined by long-term hydrological data for the Amazon basin that were recorded during the $20^{\text {th }}$ century. During this period the tendency for rainfall during the three most humid months and for the subsequent superficial runoff rate during the three months with the greatest runoff for the northeastern region of Brazil demonstrated a slow increase over long periods [2]. In 2016 the Amazon River Expedition from Peru to Brazil observed tendencies in which a prolonged ENSO (El Niño Southern Oscillation), event combined with a trend of regional warming increased the demand for water from the reservoirs of Brazilian hydroelectric plants in the Northeast, Central-West, and Southeastern regions of Brazil [3], and

caused strong rains in the Southern region of Brazil [4]. According to [5] [6] [7], this event was associated with warming that was without precedent and an extreme drought in the Amazon, compared to other strong ENSO events in 1982/83 and 1997/98. The typical conditions of drought caused by the ENSO were observed and described by [5], as occurring only in the eastern Amazon, while in the western region of the Amazon there prevailed an uncommon level of humidity. For researchers this situation can be attributed to the humid-dry dipole at the location of maximum warming of the surface of the equatorial central Pacific Ocean. About the causes of these changes are analyzed over the last two decades the average SST (Sea Surface Temperature), anomalies are weakened towards the west, in direction of the central Pacific, and this represents an indicator that needs more observation [8].

The sun emits radiation along the entire electromagnetic spectrum. The solar structure can be understood from the point of view of two regions; the interior, which goes from its center to the surface and divided into layers, while the second is the external atmosphere of constant activity in the emission of radiation and mass in the interplanetary environment. When there is an increase in the speed and concentration of the solar wind and upon reaching the earth, it causes sudden ionospheric disturbances (SID), which constitute true ionospheric storms or magnetic storms. The electromagnetic waves, UVE and $\mathrm{X}-\mathrm{R}$, do not interact with the magnetosphere and pass through it normally, but the solar wind consisting of particles (electrons and $\mathrm{He}^{+}$) collides with the magnetosphere causing a compression in the field lines, [9]. 
The variation between the phases of solar activity is 11 years, in energetic and transient phenomena since the number of explosions as well as coronal mass ejections that will constitute solar wind and the number of sunspots that is related to the polarity inversion. However, the number of dark spots on the surface, the brightness of X-rays, is more intense during half of the cycle and the other half of the cycle is less intense, [9].

\section{MATERIAL AND METHODS}

The variables involved are the number of sunspots observed from 1980 to the 2013 projection, sea surface temperature (TSM) Figs.1 and 2, variations that influence ENSO and precipitation over the city of Manaus. To show the connection between the upper and lower atmosphere, linear regression is used to obtain the interaction between the phenomena, showing through Operational Research (OR) the points of optimal connection solution within the period from 1980 to 2030 .

The coincident points on the Optimal Solution Line validate the solution that is on the resonance of phenomena over the observed period. Using statistical moments and linear regression, [10].

\section{Sample Measures}

Sample Avarege (N samples):

$$
\bar{X}=\frac{1}{N} \sum_{k=1}^{N} x_{k}
$$

Sample Variance:

$$
\sigma^{2}=\frac{1}{N-1} \sum_{k=1}^{N}\left(x^{k}-\bar{x}\right)^{2}
$$

Sample Standard Deviation:

$$
\sigma=\sqrt{\sum_{k=1}^{N} \frac{1}{N-1}\left(x^{k}-\bar{x}\right)^{2}}
$$

Sample Covariance:

$$
\sigma_{i j}=\frac{1}{N-1} \sum_{k=1}^{N}\left(x_{i j}-\bar{x}_{i}\right)\left(x_{j k}-\bar{x}_{j}\right)
$$

Sample Correlation Coefficient:

$$
r_{i j}=\frac{\sigma_{i j}}{\sigma_{i} \sigma_{j}}
$$

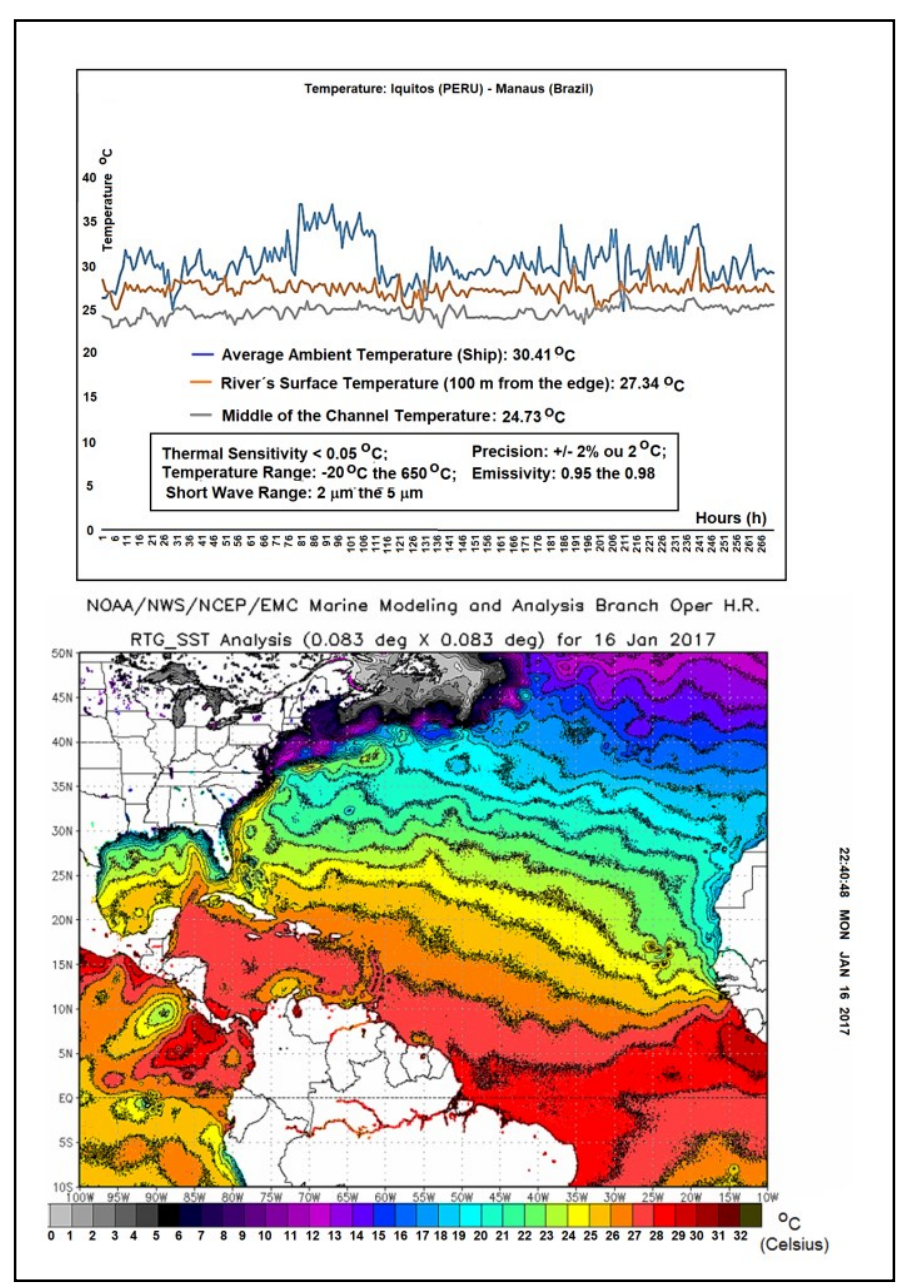

Figure. 1: Time series of temperature along the Amazon River during the first stage of the Expedition (Iquitos/Peru - Manaus/Brazil), and compared to data from the Marine Modeling and Analysis Branch Oper. H. R. (Verification Ensembles) of NOAA/NWS/NCEP/EMC. Source: Amazon River Expedition and NOAA, [11] [12]. 2016. 


\section{RESULTS AND DISCUSSION}

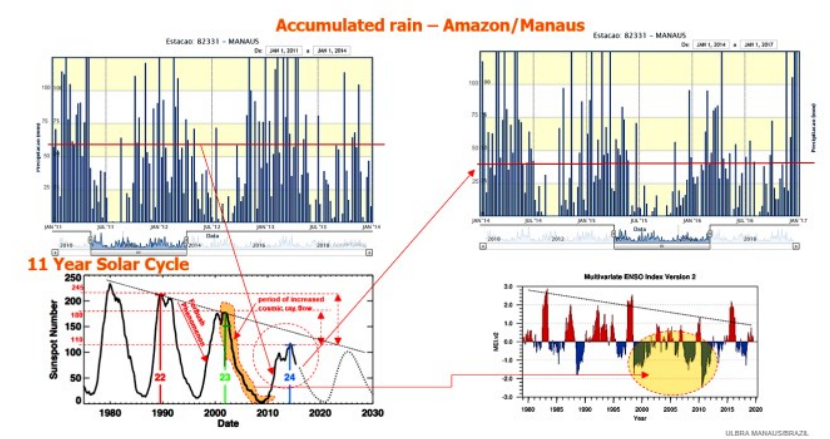

Figure. 2: Precipitation Time Series Panel, 11 Year Solar Cycle and ENSO.
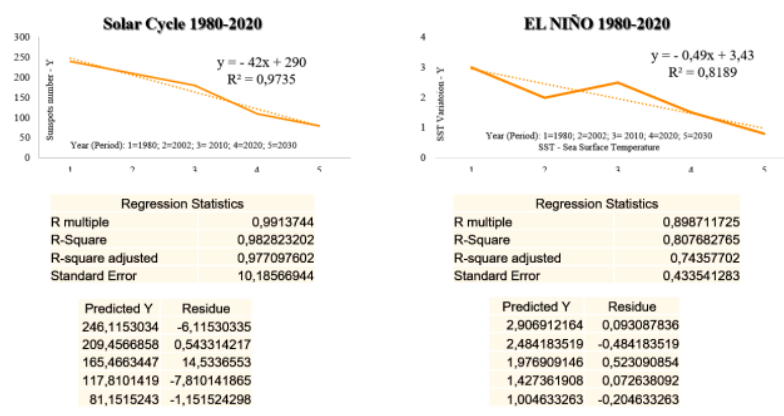

Figure. 3: Climate Statistics between 11-year Solar Cycle and ENSO (El Niño).

Figures 2 and 3 show the interrelationships between the precipitation time series over the city of Manaus (Amazonia-Brazil), the 11-year sunspot index from 1980 to 2019, and also the ENSO Multivariate index from the same period. In the comparison through investigation by operational research, it is found the strong correlation of the observed phenomena within the considered range, configuring to a tendency that the rains in the Amazon suffer from the solar cycle of 11 years of the Sun.

\section{Recommendation}

At the site [13], there is more information about the "actual state" of the Amazon River in 2016, not only with respect to climatology, but also with respect to the life of people in the communities in this region.

\section{CONCLUSION}

Although the statistical methods lead us to a great operational solution, we must always understand the method uncertainties, because we work with approximations and averages. However, the method shows a strong correlation between the phenomena.

\section{ACKNOWLEDGEMENTS}

The authors are grateful to the Lutheran University Center of Manaus (Centro Universitário Luterano, Manaus, (CEULM/ULBRA), the Foundation for the Support of Research of the State of Amazonas (Fundação de Amparo e Pesquisa do Amazonas (FAPEAM)) that provided a scholarship student to conduct the water analyses, the Max Planck Chemistry Institute (MainzGermany) for support with the chemical analyses, and the Mauá group at INPA in Manaus/Brazil. Furthermore, we thank the Secretary of Education and Quality of Teaching of the State of Amazonas.

\section{REFERENCES}

[1] M. Mohtadi; M. Prange; E. Scfub; T. Jennerjahn. Circulation in Southeastern South America and it's influence from El Niño events. Journal of the Meteorological Society of Japan, 80, 21-22. Article number: 1015 (2017) doi: 10.1038/s41467-017-00855-3n, Nature Communications.

[2] J. A. Marego; J. Tomasella; C. R. Uvo. Trends in streamflow and rainfall in tropical South America, eastern Brazil, and northwestern. Journal of Geophysical Research Atmospheres. 103: (D2) 1775-1783 (1998).

[3] CCEE - Electric Energy Trading Chamber. https://economia.uol.com.br/noticias/Reuters/2017/09/20

[4] CPTEC - INPE: Center for Weather Forecasting and Climate Studies - NATIONAL INSTITUTE OF SPACIAL RESEARCH: (Access in: http://satelite.cptec.inpe.br/home/index.jsp, (Access in: 2016, july and december).

[5] J. Jiménez-Muñoz; C. Mattar; J. Barichivich; A.Santamaria-Artigas; K. Takahashi; Y. Malhi; J. A. Sobrino; G. Schrier. Record-breaking warming and extreme drought in the Amazon rainforest during course of El Niño 2015-2016. Scientific Reports. 33130 (2016) doi: $10.1038 /$ srep33130.

[6] A. Erfanian; G. Wang; L. Fomenko. Unprecedented drought over tropical South América in 2016:significantly under-predicted by tropical SST. Scientific Reports. 5811(2017) doi: 10.1038/s415998017-05373-2.

[7] G. Poveda; O. J. Mesa. Feedbacks between hydrological processes in tropical South America and large-scale ocean-atmospheric phenomena. Journal of Climate. 2690-2702 (1997).

[8] S. Hu; A. V. Fedorov. Cross-equatorial winds control El Niño diversity and change, Nature Climate Change volume 8, pages798802 (2018).

[9] A. Roque da Silva. Nossa Estrela O SOL. Ed. Livraria da Física. Sociedade Brasileira de Física - SBF. São Paulo, 1a. Edição. (2006).

[10] Von Zuben. EA932 - DCA/FEEC/Unicamp. Tópico 8 - Fundamentos para Processos Estocásticos. (2016).

[11] ANA - CPRM - SIPAM: Hydrological Monitoring. National Water Agency - Geological Survey of Brazil - Protection System of the Amazon. Bulletin no. 18 (2016). (Access in;

https://www.cprm.gov.br/sace/boletins/Amazonas/20160513_1920160513\%20-\%20191650.pdf)

[12] NOAA/NCEP/NWS/EMC: ftp://ftpprd.ncep.noaa.gov/pub/data/nccf/com/gfs/prod. 
(Access: July/December,2016/July, 2017).

[13] N. S. Lima, N. Rio Amazonas - Expedição Fluvial - PERU/ BRASIL. ISBN 978-85-64914-76-6 (Brazil). ISBN 978-94-92633-00-2
(NETHERLANDS).

P94.

Ebook

https://sites.google.com/vew/amazonriverexpedition. 